\title{
UTILIZATION PROCESSING OF WASTE OF ALUMINA PRODUCTION INTO WATER TREATMENT REAGENTS
}

\author{
Astrelin I. \\ National Technical University of Ukraine "Igor Sikorsky Kyiv \\ Polytechnic Institute", DSc.(Engineering), Professor, Dean of Chemi- \\ cal Technology Faculty, Ukraine \\ Kosogina I. \\ National Technical University of Ukraine "Igor Sikorsky Kyiv \\ Polytechnic Institute", Ph.D., Associate Professor of the Department \\ of Inorganic Substances Water Treatment and General Chemical \\ Technology, Chemical Technology Faculty, Ukraine \\ Kyrii S. \\ National Technical University of Ukraine "Igor Sikorsky Kyiv \\ Polytechnic Institute", Ph.D. Department of Inorganic Substances \\ Water Treatment and General Chemical Technology, Chemical \\ Technology Faculty, Ukraine
}

\begin{abstract}
Continuous accumulation of waste from alumina production "red mud" leads to contamination of large land areas, reservoirs, and soils and is a potential threat of environmental catastrophe, that leads to the urgent need to find and implement rational ways of its recycling.

The most studied areas for alumina wastes recycling include the production of building materials and metals extraction. Red mud acts as a binder filler in the field of production of building materials. Products based on such filler have higher heat resistance, strength and density compared to the control samples. The obtained concrete samples are more resistant to negative temperatures due to the high alkalinity of the filler. However, analyzing the results of existing studies about precious metals extraction from the red mud, its usage in the construction industry, as soil improvers etc., we can conclude that today there are no economically and environmentally justified technologies that would allow red mud utilization in industrial-scale. This is prevented by its high alkalinity, small particle size, complex chemical and mineralogical composition.

Red mud is mainly composed of iron and aluminium oxides, which characterizes it as an attractive secondary raw material. Based on a critical analysis of the results of the work on the disposal of red mud by foreign and domestic researchers, it is possible to outline a promising direction of red mud recycling. Namely, it is the creation of water treatment reagents that can be effective for the removal of organic pollutants of natural and human-made origin. Creating water treatment reagents with the full
\end{abstract}


use of red mud as a raw material can help to solve the problem of accumulation of the latter and provide inexpensive and effective reagents in the relevant field.

\section{Introduction}

Aluminium production consists of bauxites extraction with their further purification to the aluminium oxide by the Bayer method and smelting of aluminium oxide to commercial aluminium [1]. Red mud (RM), which is formed as a by-product in the bauxite leaching process by the Bayer method, is one of the major problems of the aluminium industry in terms of resource conservation and environmental protection. According to various sources, it is established that 1 to 2 tonnes of RM is produced per 1 ton of received aluminium product [2-4]. Around 750 million tonnes of aluminium had been produced in the world over the past 20 years, and about 56 million tonnes - in 2017 alone [5]. Therefore, annually in the world dimension, respectively, from 50 to 100 million tons of RM is produced (Fig.1).

There are two alumina enterprises in Ukraine: JSC "Zaporizhzhya Aluminum Mill" and LLC "Mykolaiv Alumina Plant" (MAP). According to the State Statistics Service of Ukraine in 2017, 1.77 million tonnes of alumina waste was generated in Ukraine [6]. The sludge dump of these enterprises, where such waste is collected and accumulated, poses an extreme danger and have not been modernized for many years, which can lead to environmental accidents [7].

An example of such accidents could be the accident in Hungary, that took place on 4 October 2010 at the Ajkai Timfoldgyar Zrt aluminium plant in the Ajka city (160 kilometres from Budapest). The blast at the plant destroyed the dam, holding the waste tank. Thus, about 1.1 million $\mathrm{m}^{3}$ of red mud leaked and flooded the area in three regions of Hungary. Hungarian government declared a state of emergency and reported nearly 140 casualties [8].

In the Mykolaiv area, there was a leak at MAP (2011). The repository broke, resulting in the ejection of red mud. Because of the frost, it turned into dust, and because of the strong wind (so-called wind deflation), it swept to villages of the region. Besides, sludge dumps are potential sources of surface and groundwater contamination.

All this leads to an urgent need to find ways of alumina waste disposal. After all, the utilization of such waste is not only a means of reducing the anthropogenic load on the environment but is economi- 
cally attractive because of the red mud chemical composition and its low cost as raw material.

The purpose of the work is to analyze the existing ways of solving the problem of red mud accumulation and determination perspective direction of its recycling. Identification of critical aspects of the complex technologies application for the alumina waste utilization, aimed at both direct consumption red mud, and its transformation into a secondary resource. Recycling can be implemented mainly in three directions: first, the recovery of useful components (metals) from red mud, second, the reuse of red mud as raw materials, especially in the production of cement; third, the use of red mud in environmental processes, in particular as sorbents and coagulants in water treatment. Therefore, when solving practical problems and creating a theoretical substantiation of the treatment conditioning technologies, obtaining and using red mud as an effective sorbent of water treatment one should take into account the difficulties associated with the fineness of the particles of native sludge, with its diverse chemical and mineralogical composition.

\section{Materials}

Bauxites. This type of raw material accounts for more than $90 \%$ of world alumina production. The main aluminium-containing minerals are gibbsite $\mathrm{Al}(\mathrm{OH})_{3}$, boehmite $\mathrm{AlOOH}$ and diaspore $\mathrm{AlOOH}$ depending on the content of which, bauxite is divided into gibbsite, boehmite or diaspore. Silicon-containing minerals: kaolinite, quartz, opal, chamosite; iron-containing minerals - hematite, goethite, magnetite, siderite, pyrite. Bauxites contain impurities of calcium, gypsum and others.

Alumina worldwide production is mainly made from high quality (low silica) bauxite of the gibbsite or gibbsite-boehmite type, processed by the Bayer method. These include bauxite with a silicon modulus ( $\mathrm{mSi}$ ) above $8-10$ ( $\mathrm{mSi}$ is the ratio of $\mathrm{Al}_{2} \mathrm{O}_{3}$ to $\mathrm{SiO}_{2}$ mass).

Nefelin raw materials. Most significant interest to the aluminium, industry is nepheline concentrate $\left(29.1 \% \quad \mathrm{Al}_{2} \mathrm{O}_{3}\right)$, nepheline urtite (27.3\%) and nepheline syenite (18-24\%).

Red mud (RM) - granulometric and mineral composition of red mud can vary greatly depending on the quality of bauxite and the methods of their treatment. 
Depending on the quality of bauxite and the characteristics of its processing, red mud contains (wt.\%): 40-55 $\mathrm{Fe}_{2} \mathrm{O}_{3}, 14-18 \mathrm{Al}_{2} \mathrm{O}_{3}, 5-10$ CaO, 5-10 $\mathrm{SiO}_{2}$, 4-6 $\mathrm{TiO}_{2}, 2-4 \mathrm{Na}_{2} \mathrm{O}[9,10]$. The impurity element content is as follows $(\mathrm{g} / \mathrm{t}): 5 \mathrm{Cu}, 10 \mathrm{Be}, 50 \mathrm{~B}, 4 \mathrm{~S}, 0,2 \mathrm{Co}, 30 \mathrm{Ga}, 30$ Sc, 20 La, 30 Ce, 20 Mo, 80 Y, 20 Ni [11-17].

High humidity (up to $80 \%$ ) is a significant drawback of RM, which complicates its use. Existing sludge dewatering technologies are energy-intensive and inefficient. Also, when developing standards and technical specifications for sludge preparation, transportation and sludge usage, it should be borne in mind that with a residual humidity of $8-12 \%$ dry sludge is subject to wind deflation.

\section{Analysis of the main methods of processing ore raw materials}

Depending on the composition and physicochemical properties of the processed ore, alumina is obtained in several ways. There are three groups of processes: alkaline, acid and acid-alkaline. Nowadays, almost all alumina is obtained by alkaline methods, which in turn are subdivided into hydrochemical (Bayer method), thermal (sintering) and combined $[18,19]$.

Alkaline is the most widespread (Bayer) method and is used only for processing high-quality bauxite with a small amount (up to 5 $6 \%$ ) of silica and impurities.

Sintering methods for the processing of low-quality aluminium raw materials (low-quality bauxites, nepheline, alunite, raw clay material, kaolinite, etc.) have become widespread. The basis of sintering methods is as follows: sodium aluminates formation during heating with baking soda and the binding of silicon dioxide in its interaction with limestone in two-calcium silicate.

\section{The Bayer method}

The essence of the Bayer method is that aluminium solutions ( $\mathrm{NaOH}$ solvent) decompose rapidly with the formation of $\mathrm{Al}(\mathrm{OH})_{3}$ with the introduction of aluminium hydroxide (seed). The remaining decomposition solution can again dissolve the alumina contained in the bauxite after evaporation under vigorous stirring at $169-170{ }^{\circ} \mathrm{C}$.

Sodium aluminate and sodium silicate form insoluble sodium aluminosilicate in solution. Titanium and iron oxides, giving the residue a red colour, also pass in the insoluble residue that called red mud. After disso- 
lution, the resulting sodium aluminate is diluted with an aqueous alkali solution while reducing the temperature by $100^{\circ} \mathrm{C}$.

By Bayer method, the technological cycle of the alkaline reagent is closed. Spent on leaching reagent is released at decomposition and returns on the beginning of the process for processing new portions of ore. The original bauxite is crushed in a medium of concentrated circulating alkali solution. But simultaneously with natural aluminium hydroxides, free silica and various aluminosilicates interact with alkali, forming of sodium hydroalumosilicate insoluble in alkali. It leads to the cost of expensive alkali and the reduction of the conversion of aluminium into a solution. Therefore, it is impractical to process bauxites by Bayer method with high $\mathrm{SiO}_{2}$ content.

Aluminate solution and sludge separation are usually doing by concentration with the subsequent filtration of the solution from a thin suspension. The sludge released from the thickeners is subjected to repeated washing by the principle of counterflow. It allows for red mud being more fully washed away from the aluminate solution residues and obtain flushing water with higher concentration. The washed red mud is pumped into sludge dump.

The pure solution is subject to decomposition. For this, the solution is diluted and cooled: seed (small crystals of aluminium hydroxide) is introduced, and the slurry is stirred for 50-90 hours to obtain large enough $\mathrm{Al}(\mathrm{OH})_{3}$ crystals. Small crystals are centres of crystallization. The crystal growth interval is $52-56{ }^{\circ} \mathrm{C}$ at the beginning and $44-46{ }^{\circ} \mathrm{C}$ at the end.

For separating the hydroxide crystals from the mother liquor and classifying them by size, hydro separator, hydro cyclones and thickeners are used. The concentrated slurry is filtered and washed on drum or disk vacuum filters, with large crystals settling.

Two fractions (aluminium hydroxide and the mother liquor) receive after separation of the slurry. The large fraction (40-100 microns) is productive hydroxide and is directed to calcination. Small particles (up to 40 microns) go as a seed when decomposing aluminate solutions. The yield of aluminium hydroxide is about $65-70 \%$.

The mother liquor is combined with the wash water and sent for evaporation to a special apparatus. Excessive moisture is released there, and the concentration of caustic soda is thus increased to an optimum value for cleaning the solution of soda and some other im- 
purities. Sodium carbonate in the Bayer process is formed at the leaching stage as a result of the interaction of alkali with the carbonates of the original charge. For returning the soda to the process, it is turned into a caustic meadow by the method of limestone caustification. In this case, white sludge is obtained as a waste, which is returned for leaching or subjected to special processing.

\section{Alumina production by sintering method}

The essence of the method is the formation of sodium aluminate at high temperature as a result of the interaction mixture of aluminium ore, soda and limestone. The resulting sinter is leached with water. The solution of sodium aluminate after leaching is decomposed with carbon dioxide with aluminum hydroxide precipitating, which is calcined to obtain anhydrous alumina.

This method can process almost all types of aluminium raw materials. Nowadays it is used for processing of high silica bauxites, nepheline ores and concentrates.

The raw materials (bauxite and limestone) after grinding are fed to the mills, where they are crushed in a circulating soda solution. Some fresh soda is added there to compensate for its loss in the processing process and reversible sludge.

After leaving the refrigerator, the sinter is directed to a leach, grounding to a size of 6-8 $\mathrm{mm}$. Leaching is carried out with water and reversible weak solutions of soda.

The advantages of the method are to obtaining strong solutions containing $\mathrm{Al}_{2} \mathrm{O}_{3}$ up to $300 \mathrm{~kg} / \mathrm{m}^{3}$. But compared to the Bayer method, sintering methods require considerable energy costs. On the other hand, they are more versatile because they have lower raw material quality requirements. Such methods make it possible to process virtually any raw material (including waste) containing aluminium to alumina with a high extraction of $\mathrm{Al}_{2} \mathrm{O}_{3}$. The processing of raw materials by the method of sintering on alumina is quite advisable. In addition to alumina, in this way, soda, potash, and cement are formed as byproducts. As a result, this reduces the environmental impact and burden.

\section{Features of bauxite processing at the Mykolaiv alumina plant (MAP)}

Bauxite, which is processed by MAP, consists mainly of aluminium hydroxides (boehmite, amorphous aluminium hydroxides, gibbs- 
ite) and iron hydroxides (goethite, aluminometite, hematite, dispersed hematite), as well as of minor minerals (rutile, anatase, quartz, kaolinite, zircon, etc.). The technological scheme of processing bauxite involves grinding it in ball mills in the presence of concentrated alkaline solution with the addition of calcium hydroxide in the form of lime milk. The resulting slurry feed is pumped for further processing. The leaching of aluminium from bauxite is carried out in autoclaves with mechanical stirring. The slurry feed after separation is directed to the thickening and washing apparatus, where the aluminate solution is separated from the sludge. The last one, after six times washing, enters the sludge storage [11].

\section{Global practice processing of waste from alumina production}

Recovery of precious metals from waste from alumina production

Scientists from different countries have conducted experimental studies on the iron production from red mud [20-23]. In particular, in Central-South University (Shanghai, China) received samples of steel directly from an iron removed from RM [24]. Scientists from the Metallurgical Research Institute (China) have identified the main patterns of magnetic separation of RM for increasing the iron extraction degree from RM to $86 \%$ [25].

One way to use red mud is to restore rare earth elements. D.I. Smirnov et al. [26] developed a new method for the recovery and extract of scandium, uranium and thorium from a clay slurry of red mud by adsorption of rare earth metals by ion exchange resins with resin up to $50 \%$ by scandium. A. Xue et al. [27] proposed a recovery method of scandium from red mud more than $80 \%$ by acid dissolution. J.J. Zhang et al. obtained a solution with metal ions Ti, Sc, Fe and Al by double leaching from RM by low-concentrated hydrochloric acid [28]. A Wang-led research team also investigated Sc extraction from RM and obtained the final product with a $95 \%$ purity using hydrochloric acid as a leaching agent [29].

\section{Usage of waste from aluminium production in the construction industry}

In the construction industry, red mud can be used in the manufacture of cement, building ceramics (bricks, foam blocks, ceramic tiles, etc.), wall materials, for road construction, and as a binder in cementclay compositions. Red mud usage in the production of cement (up to 
$30 \%$ of the charge) not only reduces energy consumption but also stabilizes the cement, improves its initial strength and resistance to sulfate attack [30 - 35].

Currently, the MAP annually ships 50-60 thousand tonnes of red mud to cement plants. The potential volume of deliveries is 400-450 thousand tons per year. However, it should be taken into account the narrowing of the scale of RM utilization and its percentage in the cement mixture caused by the limitation of the total alkali content, water-soluble compounds and sludge moisture. Besides, the $\mathrm{Fe}_{2} \mathrm{O}_{3}$ content in RM is preferably greater than $50 \%$. However, specific strict standards for limiting the chemical composition of red mud for the cement industry are not yet scientifically substantiated or are absent.

Bricks production from the RM has recently have been implemented in Germany and Hungary. The firing temperature is 950 $1250{ }^{\circ} \mathrm{C}$. In the charge mixture, except for RM (51-90\%), quartz sand, volcanic rocks, silicate sludge, as well as plastic clays (7.5$15 \%$ ) use. As an alternative to traditional raw materials used in the bricks production, the RM usage can not only reduce the cost of raw materials but also has excellent environmental value. World practice shows the possibility of producing fire-resistant brick, decorative brick with black granules and ceramic tile based on RM [36 - 39]. The Shandong Aluminum Company Institute and the Great Wall Aluminum Company Institute have proposed technology of fireresistant brick production from RM and fly ash. Since from 70 to $80 \%$ of the active components $\left(\mathrm{SiO}_{2}\right.$ and $\left.\mathrm{CaO}\right)$ are recovered in $\mathrm{RM}$ and fly ash, this waste is a promising raw material for the fireresistant bricks production for reasons of cost and productivity [40].

Based on RM, quartz sand, fluorite, manganese and chromiumcontaining wastes, decorative and other black glass materials have been successfully produced, with acceptable mechanical strength, chemical resistance and optical properties [41-43].

Foam-concrete is a proven innovative trend in the development of building materials production, due to such advantages as heat insulation, fire resistance, seismic resistance. It is usually made using lime and siliceous materials and some additives. Foam concrete based on cement (15\%), lime (12 - 15\%), RM (35 - 40\%) and quartz sand (33 $35 \%$ ) were proposed to produce in China. However, it has been found to meet the lowest MU7.5 level of Chinese standards for the strength 
of concrete blocks [43]. But the technology of its production does not differ from that of other foam concrete production, so this method with the RM usage reduces the cost of foam concrete.

The prospect of using prepared RM as a part of asphalt in road construction has been determined [44]. Tests on the road stability and road strength $4 \mathrm{~km}$ long and $15 \mathrm{~m}$ wide covered with asphalt using RM as a basis, showed that this section of the road meets the requirements of the road and the standards of China [45].

The introduction of bauxite sludge as a raw material allows not only to improve the quality of the obtained products but also to increase the production profitability. High iron content in RM (up to $55 \%$ wt.) makes it promising to use it in ferrous metallurgy. Red mud is used here as an iron-containing additive in the charge for the agglomerates and pellets manufacture from iron ore concentrate for the blast furnace process. The red mud usage in, for example, blast furnace charge is prevented by the presence of up to $6 \%$ of alkali metals in the form of sodium, potassium and zirconium oxides. Studies on the red mud addition in the sintering board show that the introduction of them up to $2-5 \%$ is possible. However, it requires the development of blast furnace technology, and most importantly, the problem of RM complete disposal is not solved [46-48].

\section{Wastes from alumina production as soil ameliorant}

According to [49-50], red mud can be used as a soil ameliorant and fertilizer containing a wide range of trace elements. Thus, scientists [51] claim that the introduction of certain doses in saline soils has a positive effect on the growth and productivity of some crops (buckwheat, corn, etc.). It is claimed that RM is a more effective ameliorant in saline soils of the southern regions of Ukraine compared to phosphogypsum. Besides, red mud helps to fix calcium in the metabolic-soil complex, which prevents its displacement during salinization of soils [52]. However, despite the positive effect of red mud on soil quality and yield, according to the authors, its use is not always appropriate, especially on human-made contaminated soils. Since red mud contains an increased number of relatively mobile forms of heavy metals with migratory capacity, which can negatively affect the soil microflora, contribute to the pollution of agricultural products. 
In general, the red mud assessment by agrochemical science is not unambiguous and sometimes even contradictory. Thus, it is emphasized that the RM has a positive effect on the soil of the environment, contaminated with heavy metals [53]. This is explained by the fact that RM can absorb heavy metals ions and metals with variable valence, such as $\mathrm{Cu}^{2+}, \mathrm{Ni}^{2+}, \mathrm{Zn}^{2+}, \mathrm{Pb}^{2+}, \mathrm{Cd}^{2+}, \mathrm{Cr}^{6+}, \mathrm{Mn}^{4+}, \mathrm{Co}^{3+} \mathrm{i} \mathrm{Hg}^{2+}$. Another mechanism of heavy metals binding is based on the reaction of the red mud carbonates interaction with heavy metal ions with their deposition. In turn, the activity and reactivity of heavy metal ions in the soil decreases, the microbial activity of soils and plant development increases. W.G. Gao et al. [54] conducted some studies showing that RM can significantly reduce the content of $\mathrm{Cd}$ and $\mathrm{Zn}$ by linking mobile forms of these contaminants in soils.

R. Ciccu and co-workers [53] have also used RM to improve the quality of soils contaminated with heavy metals and declare that RM can reduce the content of heavy metals in severely contaminated soils. ther researchers have found [55] that the addition of up to $2 \%$ of RM per $1 \mathrm{~kg}$ of subsurface soil layer inhibits the uptake of $\mathrm{Cu}^{2+}, \mathrm{Ni}^{2+}$, $\mathrm{Zn}^{2+}, \mathrm{Cd}^{2+}$ by crops.

\section{Reagents from waste using in water treatment}

Since red mud of MAP contains a large number of iron, aluminium, titanium, and other compounds, it is advisable to consider and investigate the possibility of its usage in the native, packed state or composites as raw materials for coagulation and sorption reagents for water treatment [56-61]. It would contribute to the greater economization of alumina production, reduce the human-made load on the environment, provide water treatment technology with efficient and inexpensive reagents.

To date, research on the possibility of red mud using for the synthesis of coagulants and sorbents in wastewater treatment is becoming increasingly important. However, the development of red mud usage ways as a sorbent to remove contaminants from wastewater is accompanied by many problems. The main of which are high alkalinity ( $\mathrm{pH} 10$ ) and small particle size of red RM, which significantly complicates the separation of sorbents after using from treated water. Besides, red mud has a complex chemical and mineralogical composition, which significantly increases the number of factors that affect 
both the synthesis of reagents from RM and wastewater treatment processes using coagulants and sorbents based on it.

\section{The usage of reagents from secondary raw materials in coagu- lation processes}

Coagulation wastewater treatment processes are promising and widely used today. Coagulation wastewater treatment processes are promising and widely used today. Metal salts (most often iron and aluminium (iron sulfate, aluminium sulfate, iron chloride, polyaluminumchloride, oxyhydroxides of iron and aluminium)) are most often used as coagulants. Such coagulants, along with technological advantages, have certain disadvantages (high cost, corrosive effects on equipment, the dependence of the coagulation process on the $\mathrm{pH}$ medium and temperature).

To improve the efficiency of the method of destabilization of stable aqueous suspensions of wastewater, expanding the temperature range of hydrolysis processes are increasingly using complex coagulants, which contain both iron and aluminium [62, 63].

For reducing coagulants cost, it is advisable to use secondary raw materials for their synthesis.

In [64], the $\mathrm{RM} / \mathrm{MgCl}_{2}$ system was used to remove dyes from model solutions. The possibility of using a composite coagulant based on RM was investigated in paper [65]. Thus, scientists from China and Singapore have created a coagulant consisting of RM and polyaluminum chloride in different mass ratios, which is effective for phosphates removing.

\section{The usage of reagents from secondary raw materials in sorp- tion processes}

The red mud using as a sorbent for the removal of heavy metal compounds, inorganic anions (nitrates, phosphates, fluorides), organic dyes, phenol and phenol derivatives, as well as organic compounds is quite promising [66-68].

Arsenic compounds found in natural waters pose a severe threat to human life and health. Low-dose arsenic poisoning can lead to cardiovascular disorders, skin damage, hearing loss and cancer. In paper [69], the possibility of using RM-based sorbents to remove arsenic As (III) and As (V) compounds from aqueous solutions was studied. In paper [70,71], to increase the red mud adsorption capacity, its heat and acid treatment were performed with a positive result relative to 
the adsorption capacity of activated red mud. The maximum removal degree of As (V) compounds reached 96.52\%, and As (III) compounds $-87.54 \%$.

To date, a severe environmental problem, which still has no effective solution, is the wastewater pollution by hexavalent chromium compounds. In case of insufficient treatment, chromium-containing wastewater is discharged into natural reservoirs and soils, where together with vegetables and fruits the absorbed chromium compounds enter the human body, which causes malignant neoplasms, blocks enzyme systems, disrupts biological oxidation processes. In article [72], the possibility of using red mud-based sorbents to remove chromium (VI) compounds from aqueous solutions was studied.

Copper is a necessary element for the normal functioning of the human body. It is believed that the optimal copper dose in the body is 2 - $3 \mathrm{mg} /$ day. Copper deficiency in the body can develop with insufficient intake of this element (1 mg/day or less), and the toxicity threshold for humans is $200 \mathrm{mg} /$ day. At excess receipt of copper in a human body, there are functional frustrations of a nervous system (deterioration of memory, depression, insomnia). The possibility of RM-based sorbents using to remove copper compounds from aqueous solutions was studied in [73]. The mechanism of the process was presented as a surface reaction of complexation under the influence of electrostatic forces of interaction between copper ions and the adsorbent surface.

When red mud was treated by hydrogen peroxide at room temperature for $24 \mathrm{~h}$, followed by washing and drying at $100{ }^{\circ} \mathrm{C}$, in [74] a sample of sorbent with better adsorption properties in comparison with native red mud was obtained. A high removal degree (almost $100 \%$ ) of $\mathrm{Cd}$ and $\mathrm{Zn}$ compounds was achieved in the low concentrations range of the latter. In comparison, at their high concentrations, the adsorption efficiency decreased to $60-65 \%$ at $\mathrm{pH}$ values of 4.0 and 5.0, respectively.

In [75], the removal efficiency of Rhodamine B and Methylene Blue with the help of sorbents based on red mud in $92.5 \%$ and Methylene Blue $-75.0 \%$, respectively, were achieved. In [76, 77], hydrochloric acid-activated RM was used to remove Congo red from aqueous solutions. The most effective adsorption process proceeded at $\mathrm{pH}$ 7.0 with reaching equilibrium in 90 minutes. 
RM and ash after pre-treatment and acid activation were used [78] as an adsorbent to remove Methylene Blue from aqueous solutions. Activation by nitric acid helped to increase the adsorption capacity of ash and reduce the red mud adsorption capacity. This was explained by the fact decomposition of some organic and hydroxide groups, which, according to the authors, were effective adsorption centres, was not excluded during heat treatment. In our opinion, acid treatment leads to the selective dissolution of some ash components and the creation or increasing of pores and specific surface area of ash, which has the effect of increasing its adsorption capacity. According to the author, during red mud activation by nitric acid, the sorbent surface is re-charged. Due to this, there is a change in its surface properties, which increases the dye adsorption degree.

Several studies [79-81] have determined the ability of effectively RM using to remove phenol, 2-chlorophenol, 4-chlorophenol and 2,4 dichlorophenol from wastewater. It is indicated that the neutralized red mud usage to remove phenol from aqueous solutions with a maximum degree in a wide $\mathrm{pH}$ range and contact time of 10 hours must first be "neutralized" by distilled water. In paper [80], the removal of phenol from an aqueous solution using activated red mud by hydrochloric acid was considered. It was found that the maximum removal degree was obtained at $\mathrm{pH}$ below 8 and contact time 10 hours. It is established that chemisorption is the determining process in phenol removal.

In article [82] it was found the efficiency of phosphorus ions removal from contaminated water with peat is only in the range from 17 to $21 \%$, and RM in a mixture with peat - $95 \%$. Phosphate uptake by thermal and acid-activated red mud was investigated in. It was found that their removal by activated hydrochloric acid red mud is quite effective. It was found that the removal of phosphates is most effective at $\mathrm{pH}$ 7. In paper [83], the red mud was activated with concentrated hydrochloric acid with the suspension washing by distilled water and drying the residue, which was then used to remove phosphates. The study of the dose effect of treated red mud and the $\mathrm{pH}$ medium established phosphates removal degree $85 \%$.

Fluorides removal from aqueous solutions using native and by hydrochloric acid-activated red mud was studied in [84]. The maximum degree of their removal (82\%) was reached at $\mathrm{pH}$ 5.5. In paper [85], 
the nitrates removal from aqueous solutions by native and hydrochloric acid-activated red mud was investigated. The increase in the red mud sorption capacity after acid treatment is explained by the leaching of sodalite compounds, which are known to prevent adsorption by blocking free adsorption centres. The mechanism of nitrate removal, according to the authors, is explained by the chemical nature of red mud and the interaction between metal oxides and nitrate ions on the surface.

\section{Conclusions}

Since red mud contains a large number of iron, aluminium, titanium, and other compounds, it is advisable to consider and investigate the possibility of its usage in the native, packed state or composites as raw materials for coagulation and sorption reagents for water treatment. It would contribute to the greater economization of alumina production, reduce the human-made load on the environment, provide water treatment technology with efficient and inexpensive reagents.

According to the results of experimental data activated red mud can be used as a sorbent for wastewater treatment from heavy metal ions, inorganic anions (nitrates, phosphates, fluorides), organic dyes, phenol and phenol derivatives, as well as from organic compounds. The efficiency of pollutant removal depends not only on the method of red mud activation but also on several additional factors, such as adsorption duration, sorbent dose, $\mathrm{pH}$ and contaminants concentration in wastewater.

Despite the noted efficiency of sorbents based on red mud, the technology of wastewater treatment from contaminants with such sorbents is under development today. There are several reasons for this. This fact significantly complicates the possibility of theoretical substantiation of the processes that occur during the sorbents synthesis and the removal of the contaminants from wastewater.

Besides, some of the red mud components can pass into the wastewater directly during the treatment process, thereby introducing additional contamination into the water.

Red mud from different alumina enterprises can differ significantly in their chemical and phase-mineralogical composition. This fact is due to different plants use bauxite (nepheline, syenite) ore of different quality and several technologies for producing alumina. Due to this fact, the process of obtaining a sorbent based on red mud with a set of 
specific characteristics is much more complicated. Also, the red mud phase-mineralogical composition depends on the conditions and duration of its storage in the sludge dump. Therefore this causes heterogeneity in the composition of the red mud, even at the same enterprise.

RM has high alkalinity, which requires additional costs to neutralize it. Also, RM particles fineness complicates the separation process of sorbents based on red mud from wastewater solutions after their treatment.

Therefore, when solving practical problems and creating a theoretical substantiation of the treatment conditioning technologies, obtaining and using red mud as an effective sorbent for water treatment, one should take into account the difficulties, associated with the fineness of the particles of native sludge, its diverse chemical and mineralogical composition and high alkalinity.

One of the possible directions of solving the RM involving in recycling problem may be the extraction of active components (metal oxides) of the future sorbent from the red mud and their application on a porous granular carrier. It can help to easily separate the resulting sorbent from the treated wastewater, prevent additional contamination (because the sorbent will contain only the target components, mainly applied to the porous carrier) and facilitate the process of adapting the technology of sorbent obtaining from red mud of different enterprises.

References

1. Rai, S., Wasewar, K. L., Lataye, D. H., Mishra, R. S., Puttewar, S. P., Chaddha, M. J., Mukhopadhyay, J. (2012). Neutralization of red mud with pickling waste liquor using Taguchi's design of experimental methodology. Waste Management \& Research, 30(9), 922-930. doi: 10.1177/0734242x12448518

2. Li, J., Xu, L., Sun, P., Zhai, P., Chen, X., Zhang, H., ... Zhu, W. (2017). Novel application of red mud: Facile hydrothermal-thermal conversion synthesis of hierarchical porous $\mathrm{AlOOH}$ and $\mathrm{Al} 2 \mathrm{O} 3$ microspheres as adsorbents for dye removal. Chemical Engineering Journal, 321, 622-634. doi: 10.1016/j.cej.2017.03.135

3. Li, J., Xu, L., Sun, P., Zhai, P., Chen, X., Zhang, H., ... Zhu, W. (2017). Novel application of red mud: Facile hydrothermal-thermal conversion synthesis of hierarchical porous $\mathrm{AlOOH}$ and $\mathrm{Al} 2 \mathrm{O} 3$ microspheres as adsorbents for dye removal. Chemical Engineering Journal, 321, 622-634. doi: 10.1016/j.cej.2017.03.135

4. Kumar, S., Kumar, R., \& Bandopadhyay, A. (2006). Innovative methodologies for the utilisation of wastes from metallurgical and allied 
industries. Resources, Conservation and Recycling, 48(4), 301-314. doi: 10.1016/j.resconrec.2006.03.003

5. .the website of the International Aluminium Institute. (n.d.). Retrieved from http://www.world-aluminium.org/statistics/

6. (n.d.). Retrieved from http://www.ukrstat.gov.ua/.

7. Ahn, J. W., Thriveni, T., \& Nam, S. Y. (2015). Sustainable Recycling Technologies for Bauxite Residue (Red Mud) Utilization. Energy Technology 2015, 173-179. doi: 10.1007/978-3-319-48220-0_19

8. Последствия техногенной катастрофы в Венгрии. (n.d.). Retrieved from http://animalworld.com.ua/news/Posledstvija-tehnogennoj-katastrofy-v-Vengrii

9. Oh, C. J., Yi, Y. K., Kim, S. J., Tran, T., \& Kim, M. J. (2013). Production of micro-crystalline boehmite from hydrothermal processing of Bayer plant alumina tri-hydrate. Powder Technology, 235, 556-562. doi: 10.1016/j.powtec.2012.10.041

10. Paramguru, R. K., Rath, P. C., \& Misra, V. N. (2004). Trends In Red Mud Utilization - A Review. Mineral Processing and Extractive Metallurgy Review, 26(1), 1-29. doi: 10.1080/08827500490477603

11. Habashi, F. (2013). A Hundred Years of the Bayer Process for Alumina Production. Essential Readings in Light Metals, 83-93. doi: 10.1002/9781118647868.ch12

12. Sutar, H. (2014). Progress of Red Mud Utilization: An Overview. American Chemical Science Journal, 4(3), 255-279. doi: 10.9734/acsj/2014/7258

13. Sglavo, V. M., Campostrini, R., Maurina, S., Carturan, G., Monagheddu, M., Budroni, G., \& Cocco, G. (2000). Bauxite 'red mud' in the ceramic industry. Part 1: thermal behaviour. Journal of the European Ceramic Society, 20(3), 235-244. doi: 10.1016/s0955-2219(99)00088-6

14. Altundoğan, H., Altundoğan, S., Tümen, F., \& Bildik, M. (2002). Arsenic adsorption from aqueous solutions by activated red mud. Waste Management, 22(3), 357-363. doi: 10.1016/s0956-053x(01)00041-1

15. Srikanth, S., Ray, A. K., Bandopadhyay, A., Ravikumar, B., \& Jha, A. (2005). Phase Constitution During Sintering of Red Mud and Red Mud-Fly Ash Mixtures. Journal of the American Ceramic Society, 88(9), 2396-2401. doi: 10.1111/j.1551-2916.2005.00471.x

16. Vachon, P., Tyagi, R. D., Auclair, J. C., \& Wilkinson, K. J. (1994). Chemical and biological leaching of aluminum from red mud. Environmental Science \& Technology, 28(1), 26-30. doi: 10.1021/es00050a005

17. Snars, K., \& Gilkes, R. (2009). Evaluation of bauxite residues (red muds) of different origins for environmental applications. Applied Clay Science, 46(1), 13-20. doi: 10.1016/j.clay.2009.06.014

18. Ruys, A. (2019). Refining of alumina: The Bayer process. Alumina Ceramics, 49-70. doi: 10.1016/b978-0-08-102442-3.00003-8

19. Hand, R. D. (2013). Alumina Yield in the Bayer Process. Essential Readings in Light Metals, 522-527. doi: 10.1002/9781118647868.ch72

20. Yang, Y., Wang, X., Wang, M., Wang, H., \& Xian, P. (2015). Recovery of iron from red mud by selective leach with oxalic acid. Hydrometallurgy, 157, 239245. doi: 10.1016/j.hydromet.2015.08.021 
21. Yi, R. R., \& Cao, W. (2014). Current Situation and Prospect of Comprehensive Utilization of Red Mud. Applied Mechanics and Materials, 522-524, 811-816. doi: 10.4028/www.scientific.net/amm.522-524.811

22. Borra, C. R., Blanpain, B., Pontikes, Y., Binnemans, K., \& Gerven, T. V. (2015). Smelting of Bauxite Residue (Red Mud) in View of Iron and Selective Rare Earths Recovery. Journal of Sustainable Metallurgy, 2(1), 28-37. doi: 10.1007/s40831-015-0026-4

23. Ghosh, I., Guha, S., Balasubramaniam, R., \& Kumar, A. R. (2011). Leaching of metals from fresh and sintered red mud. Journal of Hazardous Materials, 185(2-3), 662-668. doi: 10.1016/j.jhazmat.2010.09.069

24. Reddy, N. G., \& Rao, B. H. (2016). Evaluation of the Compaction Characteristics of Untreated and Treated Red Mud. Geo-Chicago 2016. doi: 10.1061/9780784480151.003

25. Liu, S., He, A., Wu, N., \& Zeng, J. (2019). Physical Simulation of Recovering Cast iron from Bayer Red Mud. Procedia Manufacturing, 37, 443-449. doi: 10.1016/j.promfg.2019.12.072

26. Smirnov, D., \& Molchanova, T. (1997). The investigation of sulphuric acid sorption recovery of scandium and uranium from the red mud of alumina production. Hydrometallurgy, 45(3), 249-259. doi: 10.1016/s0304-386x(96)00070-9

27. Liu, Z., Li, H., \& Zhao, Z. (2017). Selective Recovery of Scandium From Sulfating Roasting Red Mud By Water Leaching. Rare Metal Technology 2017 The Minerals, Metals \& Materials Series, 255-264. doi: 10.1007/978-3-319-51085-9_27

28. Raghavan, P. K. N., Kshatriya, N. K., \& Wawrynink, K. (2011). Recovery of Metal Values from Red Mud. Light Metals 2011, 103-106. doi: 10.1007/978-3319-48160-9_18

29. Zhang, X., Zhou, K., Wu, Y., Lei, Q., Peng, C., \& Chen, W. (2019). Separation and recovery of iron and scandium from acid leaching solution of red mud using D201 resin. Journal of Rare Earths. doi: 10.1016/j.jre.2019.12.005

30. Pan, Z., Cheng, L., Lu, Y., \& Yang, N. (2002). Hydration products of alkali-activated slag-red mud cementitious material. Cement and Concrete Research, 32(3), 357-362. doi: 10.1016/s0008-8846(01)00683-4.

31. Kalkan, E. (2006). Utilization of red mud as a stabilization material for the preparation of clay liners. Engineering Geology,87(3-4), 220-229. doi: 10.1016/j.enggeo.2006.07.002

32. Liu, X., Zhang, N., Sun, H., Zhang, J., \& Li, L. (2011). Structural investigation relating to the cementitious activity of bauxite residue - Red mud. Cement and Concrete Research, 41(8), 847-853. doi: 10.1016/j.cemconres.2011.04.004

33. Kang, S.-P., \& Kang, H.-J. (2017). Pore and Efflorescence Characteristics of Alkali Activated Slag-Red Mud Cement Mortar depending on Red Mud Content. Journal of the Korea Institute of Building Construction, 17(3), 261-268. doi: 10.5345/jkibc.2017.17.3.261

34. Pan, Z., Li, D., Yu, J., \& Yang, N. (2003). Properties and microstructure of the hardened alkali-activated red mud-slag cementitious material. Cement and Concrete Research, 33(9), 1437-1441. doi: 10.1016/s0008-8846(03)00093-0 
35. Experimental Investigation On Replacement Of Cement With Fly-Ash, Steel Slag, Red Mud In Concrete. (2017). International Journal of Recent Trends in Engineering and Research, 3(3), 186-193. doi: 10.23883/ijrter.2017.3065.mg8oy

36. Pan, L., \& Han, C. (2012). Research on the Performance of the Autoclaved Fly Ash Common Brick. Advanced Materials Research, 424-425, 660-664. doi: 10.4028/www.scientific.net/amr.424-425.660

37. Zhang, X., Yan, Y., Yang, L., Xie, F. L., \& Hu, Z. H. (2013). Investigation on the Performances of High Volume White Mud-Fly Ash Brick. Advanced Materials Research, 788, 640-645. doi: 10.4028/www.scientific.net/amr.788.640

38. Ma, L., \& Li, G. Z. (2013). Activator on Properties of Red Mud Lightweight Baking-Free Brick. Applied Mechanics and Materials, 468, 36-38. doi: 10.4028/www.scientific.net/amm.468.36

39. Yalçın, N., \& Sevinç, V. (2000). Utilization of bauxite waste in ceramic glazes. Ceramics International, 26(5), 485-493. doi: 10.1016/s0272-8842(99)000838

40. Liu, D.-Y., \& Wu, C.-S. (2012). Stockpiling and Comprehensive Utilization of Red Mud Research Progress. Materials, 5(7), 1232-1246. doi: $10.3390 /$ ma5071232

41. Jiang, C. (2020). Recycling Fly Ash And Red Mud To Manufacture SelfFoaming Ceramic Foams. Ceramics - Silikaty, 1-9. doi: 10.13168/cs.2020.0011

42. Cheng, T., \& Chen, Y. (2004). Characterisation of glass ceramics made from incinerator fly ash. Ceramics International, 30(3), 343-349. doi: 10.1016/s0272-8842(03)00106-8

43. Ye, Z. N., Wang, Y. W., Jiang, H., Li, N., \& Liu, S. Q. (2013). Foamed Glass-Ceramics Made from Red-Mud. Key Engineering Materials, 575-576, 461464. doi: 10.4028/www.scientific.net/kem.575-576.461

44. Wang, R. Y., \& Zhang, L. F. (2011). Study on Mechanical Property and Strength Formation Mechanism of Red-Mud and Fly-Ash Aerated Concrete. Advanced Materials Research, 243-249, 2653-2656. doi: 10.4028/www.scientific.net/amr.243-249.2653

45. Chen, X., Lu, A., \& Qu, G. (2013). Preparation and characterization of foam ceramics from red mud and fly ash using sodium silicate as foaming agent. Ceramics International, 39(2), 1923-1929. doi: 10.1016/j.ceramint.2012.08.042

46. Bhat, A., \& Banthia, A. (2007). Improvement of the Red Mud PolymerMatrix Composites by Organophillization of Red Mud. Advanced Materials Research, 29-30, 333-336. doi: 10.4028/www.scientific.net/amr.29-30.333

47. Fang, Y. G., \& Peng, Q. (2010). Study on Red Mud as Secondary Resource for Iron Concentration. Advanced Materials Research, 113-116, 2271-2277. doi: 10.4028/www.scientific.net/amr.113-116.2271

48. Pera, J., Boumaza, R., \& Ambroise, J. (1997). Development of a pozzolanic pigment from red mud. Cement and Concrete Research, 27(10), 1513-1522. doi: 10.1016/s0008-8846(97)00162-2

49. Gong, C., \& Yang, N. (2000). Effect of phosphate on the hydration of alkaliactivated red mud-slag cementitious material. Cement and Concrete Research, 30(7), 1013-1016. doi: 10.1016/s0008-8846(00)00260-x 
50. Vocke, G. F. (n.d.). Economic and environmental impacts on U.S. agriculture from insecticide, fertilizer, soil loss, and animal waste regulatory policies. doi: 10.31274/rtd-180816-5354

51. Franz, M. (2008). Phosphate fertilizer from sewage sludge ash (SSA). Waste Management, 28(10), 1809-1818. doi: 10.1016/j.wasman.2007.08.011

52. Ma, C. J., Naidu, R., \& Ming, H. (2014). The Influence of Amendment to the Red Mud and the Effects of Rehabilitated Red Mud on Sweet Sorghum Seedlings. Advanced Materials Research, 1073-1076, 216-221. doi: 10.4028/www.scientific.net/amr.1073-1076.216

53. Mucsi, G., Szabó, R., Rácz, Á., Kristály, F., \& Kumar, S. (2019). Combined Utilization Of Red Mud And Mechanically Activated Fly Ash In Geopolymers. Rudarsko-Geološko-Naftni Zbornik, 34(1), 27-36. doi: 10.17794/rgn.2019.1.3

54. Ciccu, R., Ghiani, M., Serci, A., Fadda, S., Peretti, R., \& Zucca, A. (2003). Heavy metal immobilization in the mining-contaminated soils using various industrial wastes. Minerals Engineering, 16(3), 187-192. doi: 10.1016/s08926875(03)00003-7

55. Liang, Z., Peng, X., \& Luan, Z. (2011). Immobilization of Cd, Zn and Pb in sewage sludge using red mud. Environmental Earth Sciences, 66(5), 1321-1328. doi: 10.1007/s12665-011-1341-0

56. Lombi, E., Zhao, F.-J., Wieshammer, G., Zhang, G., \& Mcgrath, S. P. (2002). In situ fixation of metals in soils using bauxite residue: biological effects. Environmental Pollution, 118(3), 445-452. doi: 10.1016/s02697491(01)00295-0

57. Poulin, É., Blais, J.-F., \& Mercier, G. (2008). Transformation of red mud from aluminium industry into a coagulant for wastewater treatment. Hydrometallurgy, 92(1-2), 16-25. doi: 10.1016/j.hydromet.2008.02.004

58. Kosogina, I. V., Astrelin, I. M., \& Stasyuk, N. V. (2013). Coagulation reagent from alumina production waste. Odes'Kyi Politechnichnyi Universytet. Pratsi, 281-285. doi: 10.15276/opu.3.42.2013.57

59. Kyrii S., Kosogina I., Astrelin I., Kyrienko O. (2015). The efficiency of coagulation treatment wastewater by reagent obtained from waste alumina production. Research Bulletin of the National Technical University of Ukraine "Kyiv Polytechnic Institute", 0(6), 95-101. doi: 10.20535/1810-0546.2015.6.51173

60. Kulishenko, A. E., Klimenko, N. A., Grechanik, S. V., Kravchenko, T. B., Kostyuk, V. A., Avramenko, L. P., \& Kosogina, I. V. (2018). The Use of Products of Recycling Waste of Aluminum Manufacturing as a Coagulant when Purifying Highly Colored Natural Water. Journal of Water Chemistry and Technology, 40(5), 265-271. doi: 10.3103/s1063455x1805003x

61. S.O. Kyrii, I.V. Kosogina, I.M. Astrelin, L.S. Obodenko. (2018) Investigation of the properties of activated carbon modified by wastes of alumina production. Voprosy khimii i khimicheskoi tekhnologii. 2.,70-78. EID: 2-s2.085045314154

62. Kyrii, S. O., Kosogina, I. V., Astrelin, I. M., \& Mosiyuk, V. Y. (2017). Utilization of "red mud" being a part of new effective adsorbent in water 
treatment. Water And Water Purification Technologies. Scientific And Technical News, 21(1), 3-11. doi: 10.20535/2218-93002112017121418

63. Ni, F., Peng, X., Zhao, Y., He, J., Li, Y., \& Luan, Z. (2012). Preparation of coagulant from red mud and semi-product of polyaluminum chloride for removal of phosphate from water. Desalination And Water Treatment, 40, 153-158. doi: 10.5004/dwt.2012.2771

64. Sushil, S., \& Batra, V. S. (2008). Catalytic applications of red mud, an aluminium industry waste: A review. Applied Catalysis B: Environmental, 81(1-2), 64-77. doi: 10.1016/j.apcatb.2007.12.002

65. Wang, Q., Luan, Z., Wei, N., Li, J., \& Liu, C. (2009). The color removal of dye wastewater by magnesium chloride/red mud (MRM) from aqueous solution. Journal of Hazardous Materials, 170(2-3), 690-698. doi: 10.1016/j.jhazmat.2009.05.011

66. Ni, F., He, J., Wang, Y., \& Luan, Z. (2015). Preparation and characterization of a cost-effective red mud/polyaluminum chloride composite coagulant for enhanced phosphate removal from aqueous solutions. Journal of Water Process Engineering, 6, 158-165. doi: 10.1016/j.jwpe.2015.04.003

67. Zhu, X. F., Liu, H. Y., Shi, P. H., Wu, J. F., \& Guo, Y. F. (2011). Removal of Phosphate from Aqueous Solution by Using Red Mud. Advanced Materials Research, 291-294, 1804-1807. doi: 10.4028/www.scientific.net/amr.291-294.1804

68. Tangde, V. M., Prajapati, S. S., Mandal, B. B., \& Kulkarni, N. P. (2017). Study of Kinetics and Thermodynamics of Removal of Phosphate from Aqueous Solution using Activated Red Mud. International Journal of Environmental

69. Tor, A., Danaoglu, N., Arslan, G., \& Cengeloglu, Y. (2009). Removal of fluoride from water by using granular red mud: Batch and column studies. Journal of Hazardous Materials, 164(1), 271-278. doi: 10.1016/j.jhazmat.2008.08.011

70. Altundoğan, H. S., Altundoğan, S., Tümen, F., \& Bildik, M. (2000). Arsenic removal from aqueous solutions by adsorption on red mud. Waste Management, 20(8), 761-767. doi: 10.1016/s0956-053x(00)00031-3

71. Altundoğan, H., Altundoğan, S., Tümen, F., \& Bildik, M. (2002). Arsenic adsorption from aqueous solutions by activated red mud. Waste Management, 22(3), 357-363. doi: 10.1016/s0956-053x(01)00041-1

72. Thinh, P. T. H. (2018). Modification of oxidized activated carbon surface bY $\mathrm{Fe}$ and $\mathrm{Mn}$ for arsenic removal from aquerous solution. Vietnam Journal of Science and Technology, 56(2C), 80-87. doi: 10.15625/2525-2518/56/2c/13033

73. Pradhan, J., Das, S. N., \& Thakur, R. S. (1999). Adsorption of Hexavalent Chromium from Aqueous Solution by Using Activated Red Mud. Journal of Colloid and Interface Science, 217(1), 137-141. doi: 10.1006/jcis.1999.6288

74. Agrawal, A., Sahu, K. K., \& Pandey, B. D. (2004). A comparative adsorption study of copper on various industrial solid wastes. AIChE Journal, 50(10), 2430-2438. doi: 10.1002/aic.10206 
75. Gupta, V. K., \& Sharma, S. (2002). Removal of Cadmium and Zinc from Aqueous Solutions Using Red Mud. Environmental Science \& Technology, 36(16), 3612-3617. doi: 10.1021/es020010v

76. Gupta, V. K., Suhas, Ali, I., \& Saini, V. K. (2004). Removal of Rhodamine B, Fast Green, and Methylene Blue from Wastewater Using Red Mud, an Aluminum Industry Waste. Industrial \& Engineering Chemistry Research, 43(7), 1740-1747. doi: $10.1021 / \mathrm{ie} 034218 \mathrm{~g}$

77. Tor, A., \& Cengeloglu, Y. (2006). Removal of congo red from aqueous solution by adsorption onto acid activated red mud. Journal of Hazardous Materials, 138(2), 409-415. doi: 10.1016/j.jhazmat.2006.04.063

78. Namasivayam, C., \& Arasi, D. (1997). Removal of congo red from wastewater by adsorption onto waste red mud. Chemosphere, 34(2), 401-417. doi: 10.1016/s0045-6535(96)00385-2

79. Wang, S., Boyjoo, Y., Choueib, A., \& Zhu, Z. (2005). Removal of dyes from aqueous solution using fly ash and red mud. Water Research, 39(1), 129-138. doi: 10.1016/j.watres.2004.09.011

80. Gupta, V. K., Ali, I., \& Saini, V. K. (2004). Removal of Chlorophenols from Wastewater Using Red Mud: An Aluminum Industry Waste. Environmental Science \& Technology, 38(14), 4012-4018. doi: 10.1021/es049539d

81. Tor, A., Cengeloglu, Y., \& Ersoz, M. (2009). Increasing the phenol adsorption capacity of neutralized red mud by application of acid activation procedure. Desalination, 242(1-3), 19-28. doi: 10.1016/j.desal.2008.03.028

82. Tor, A., Cengeloglu, Y., Aydin, M. E., \& Ersoz, M. (2006). Removal of phenol from aqueous phase by using neutralized red mud. Journal of Colloid and Interface Science, 300(2), 498-503. doi: 10.1016/j.jcis.2006.04.054

83. Udert, K. M. (2018). Phosphorus as a resource. Phosphorus: Polluter and Resource of the Future - Removal and Recovery from Wastewater, 57-80. doi: 10.2166/9781780408361_057

84. Loc, D. T. T. (2018). Phosphate Removal From Aqueous Solution By Using Modified Sludge From Water Treatment Plant. Vietnam Journal of Science and Technology, 56(2C), 43-49. doi: 10.15625/2525-2518/56/2c/13028

85. Çengeloglu, Y. (2002). Removal of fluoride from aqueous solution by using red mud. Separation and Purification Technology, 28(1), 81-86. doi: 10.1016/s13835866(02)00016-3

86. Cengeloglu, Y., Tor, A., Ersoz, M., \& Arslan, G. (2006). Removal of nitrate from aqueous solution by using red mud. Separation and Purification Technology, 51(3), 374-378. doi: 10.1016/j.seppur.2006.02.020 